\title{
Supramolecular Architecture and Electrical Properties of a Perylene Derivative in Physical Vapor Deposited Films
}

\author{
José Diego Fernandes ${ }^{a}$, Pedro Henrique Benites Aoki ${ }^{a, b}$, Ricardo Flavio Aroca ${ }^{c}$, \\ Wagner Dias Macedo Junior ${ }^{a}$, Agda Eunice de Souza ${ }^{a}$, Silvio Rainho Teixeira ${ }^{a}$, \\ Maria Luiza Braunger ${ }^{a}$, Clarissa de Almeida Olivatia ${ }^{,}$Carlos José Leopoldo Constantino ${ }^{a}$ \\ ${ }^{a}$ Departamento de Física, Química e Biologia, Faculdade de Ciências e Tecnologia, \\ UNESP Univ Estadual Paulista, Presidente Prudente, SP, Brazil \\ ${ }^{b}$ Instituto de Física de São Carlos - IFSC, Universidade de São Paulo-USP, São Carlos, SP, Brazil \\ ${ }^{c}$ Materials and Surface Science Group, University of Windsor, Windsor, On, N9B3P4, Canada
}

Received: November 12, 2014; Revised: July 28, 2015

\begin{abstract}
The supramolecular structure of organic thin films is a key factor in their optical and electrical properties and, consequently, in the technological applications involving organic electronic. Here, thin films of a perylene derivative, the bis butylimido perylene (BuPTCD), were produced by vacuum thermal evaporation (PVD, physical vapor deposition). The main objective is to investigate the supramolecular structure of the BuPTCD in these PVD films, which implies to control their thickness at nanometer scale and to determine their molecular organization, morphology at micro and nanometer scales and crystallinity. The ultraviolet-visible absorption reveals a uniform growth of the PVD films. The optical and atomic force microscopy images show a homogeneous surface of the film at micro and nanometer scales, respectively. The X-ray diffraction indicates that both powder and PVD film are in the crystalline form. Complementary, a preferential head-on orientation of the molecules in the PVD films is determined via infrared absorption spectroscopy. Besides, the annealing process $\left(200^{\circ} \mathrm{C}\right) \mathrm{did}$ not affect the molecular organization of the PVD films, revealing a thermal stability of the BuPTCD molecules within the PVD films. Through DC electrical measurements, an electrical conductivity of $7.45 \times 10^{-10} \mathrm{~S} / \mathrm{m}$ was determined for BuPTCD PVD films onto Au interdigitated electrodes (IDE-structured devices), which can be enhanced, under illumination, by two orders of magnitude (photoconductivity effect). As proof-of-concept, the IDE-structured devices are tested as gas sensor for trifluoroacetic acid.
\end{abstract}

Keywords: supramolecular structure, thin films, perylene derivative, electrical measurements

\section{Introduction}

Nanostructured films of organic materials have played central role in the design of new electronic devices ${ }^{1}$. In this context, perylene derivatives stand out due to their suitable optical and electrical properties besides the low cost of processing in comparison to the conventional semiconducting materials ${ }^{2-6}$. Also noteworthy is its high absorption of electromagnetic radiation in the visible and near infrared region $^{7,8}$. Therefore, a broad range of application is based on perylene thin films, such as light-emitting diodes (LEDs), ${ }^{9}$ transistors, ${ }^{10}$ solar cells ${ }^{8}$ and a variety of sensors for detecting dopamine, ${ }^{11}$ pesticides ${ }^{7}$ and metallic ions ${ }^{12,13}$.

Langmuir, ${ }^{14,15}$ Langmuir-Blodgett (LB), ${ }^{16,17}$ Layer-by-Layer (LbL), ${ }^{16,18}$ spin-coating, ${ }^{19,20}$ casting $^{21,22}$ and physical vapor deposition (PVD) ${ }^{10,23}$ techniques are the most frequently applied in the fabrication of organic-based nanostructured films. In particular, PVD is one of the most common deposition technologies of small organic molecules, displaying high control on the supramolecular architecture of the films ${ }^{24,25}$ Indeed, the molecular organization plays an important role and mediates the electrical and optical properties of the films

*e-mail: diegofernandes.unesp@hotmail.com toward optimization of the device performance ${ }^{26}$. The relevance of the technique can be understood from the results found in the manufacture of organic light emitting diodes (OLEDs) ${ }^{27}$ and transistors, ${ }^{28}$ for instance. Greater efficiency in charge mobility was found for films produced via PVD, which is a direct consequence of the molecular orientation, given by the face-to-face stacking of the deposited molecules ${ }^{27}$.

Therefore, the elucidation of the supramolecular architecture of thin films is crucial, prior to technological applications. That is our main objective here for PVD films of the perylene derivative bis butylimido perylene (BuPTCD). The growth of BuPTCD PVD films was monitored by ultraviolet-visible (UV-Vis) absorption spectroscopy and the morphology analyzed at nano and micrometer scales using atomic force microscopy (AFM) and micro-Raman, respectively. The crystallinity was inferred by X-ray diffraction and the molecular organization was extracted from FTIR absorption spectra obtained in transmission and reflection modes, analyzed using the surface selections rules ${ }^{29,30}$. Finally, DC electrical analysis of the BuPTCD PVD film was performed onto Au interdigitated electrodes (IDE). 


\section{Material and Methods}

The purified sample of bis butylimido perylene (BuPTCD) was provided by Dr. J. Duff from the Xerox Resource Centre of Canada. BuPTCD solution was prepared with $10 \%$ trifluoroacetic acid (TFA) in dichloromethane since the dye is insoluble in organic solvents. The thermal stability of BuPTCD powder was characterized through thermogravimetry (TG) and differential scanning calorimetry (DSC) using a TA Instruments, model SDT Q600, $\mathrm{AlO}_{2}$ crucible, approximately $14 \mathrm{mg}$ of sample and $10^{\circ} \mathrm{C} / \mathrm{min}$ heating rate. The thermal treatment was performed from 20 to $800^{\circ} \mathrm{C}$, under air atmosphere $(100 \mathrm{~mL} / \mathrm{min})$.

The PVD films were grown using the vacuum thermal evaporation technique in a Boc Edwards machine, model Auto 306, under $10^{-6}$ Torr (chamber vacuum). The method consists of placing the BuPTCD powder in a Ta boat where an electric current is applied to promote the evaporation of the material. The electric current was adjusted slowly up to $1.4 \mathrm{~A}$, leading to an evaporation rate between 0.1 and $0.5 \mathrm{~nm} / \mathrm{s}$, monitored by a quartz crystal microbalance. The PVD films were deposited in five evaporation steps. For each step, a mass of $5.0 \mathrm{mg}$ was weighted and then placed in the Ta boat to be evaporated. This procedure avoids fusing the powder due to long periods of heating, which may compromise the regularity of the evaporation process and, consequently, the control of the film growth and its quality.

The PVD films were deposited onto quartz plates up to $100 \mathrm{~nm}$ and monitored via UV-Vis absorption spectroscopy using a Varian spectrophotometer, model Cary 50, from 190 to $1100 \mathrm{~nm}$. The PVD films onto quartz substrates were also characterized morphologically at micrometer scale combining Raman scattering and optical microscopy using a micro-Raman Renishaw spectrograph, model in-Via. The molecular organization of PVD films was determined by means of FTIR absorption spectroscopy using a spectrometer Bruker, model Tensor 27, between 600 and $4000 \mathrm{~cm}^{-1}$, spectral resolution of $4 \mathrm{~cm}^{-1}$, and 128 scans. The $100 \mathrm{~nm}$ BuPTCD PVD films were deposited simultaneously onto Ge plate for transmission mode and Ag mirror for reflection mode. BuPTCD powder dispersed in $\mathrm{KBr}$ pellet was also characterized through FTIR and used as reference of a system with random molecular organization. The PVD films were also annealed up to $200{ }^{\circ} \mathrm{C}$ at environmental atmosphere for $2 \mathrm{~h}$ with heating rate of $10^{\circ} \mathrm{C} / \mathrm{min}$, in order to evaluate the influence of the heating on the PVD film molecular organization.

The crystallinity of BuPTCD was determined by X-ray diffraction using a Shimadzu diffractometer, model XRD-6000, with $\mathrm{Cu}-\kappa \alpha_{1}(\lambda=1.5406 \AA)$ and $\mathrm{Cu}-\kappa \alpha_{2}(\lambda=1.5444 \AA)$ radiation, $40 \mathrm{kV}, 30 \mathrm{~mA}$. The scan was done at intervals of $2 \theta$ angles from $5^{\circ}$ to $70^{\circ}$, using divergence and reception slits of $1^{\circ}$, with a step of $0.02^{\circ}$ and a scan rate of $2 \% \mathrm{~min}$ for both powder and 100nm PVD films deposited on BK7-glass slides. The $100 \mathrm{~nm}$ PVD films deposited onto quartz and Ge plates were also characterized morphologically at nanometer scale through AFM images recorded using a Nanosurf microscope, model easy Scan 2, tip of silicon nitride and tapping mode. The topographic images were analyzed using the software Gwyddion2.19 to obtain parameters such as average height and roughness.
The electrical characterization was carried out by depositing $100 \mathrm{~nm}$ of BuPTCD PVD film onto Au interdigitated electrodes (IDE-structured device). The IDE were fabricated by photolithography with the following parameters: 25 pars of digits with $100 \mathrm{~nm}$ height, $8 \mathrm{~mm}$ length, $100 \mu \mathrm{m}$ width, and separated from each other by $100 \mu \mathrm{m}$. A Keithley 238 voltage source was applied to obtain current versus voltage (I vs. V) and to calculate the electrical conductivity of BuPTCD film on IDE-structured devices. Photoconductivity effect was evaluated by current versus time (I vs. t) measurements applying $5 \mathrm{~V}$ in the dark and under illumination from a halogen lamp $\left(150 \mathrm{~mW} / \mathrm{cm}^{2}\right)$. The possible application of BuPTCD as a trifluoroacetic acid (TFA) gas sensor was also explored. A voltage of $5 \mathrm{~V}$ was applied and the current through the IDE-structured device was measured as a function of time (I vs. t) upon addition of 5 microsyringes of $250 \mu \mathrm{L}$ with TFA gas in to the sample chamber.

\section{Results and Discussion}

\subsection{BuPTCD PVD films: growth and morphology}

The BuPTCD thermal degradation was investigated via TG analysis. Figure 1 shows the TG curve and its first derivative (DTG), revealing high thermal stability until ca. $380^{\circ} \mathrm{C}$. After that it is observed a small mass loss of $3.86 \%$ between 25 and $400^{\circ} \mathrm{C}$ and $96 \%$ between 400 to $664^{\circ} \mathrm{C}$ with maximum at $650^{\circ} \mathrm{C}$ (DTG). Both endothermic and exothermic events are not seen on DSC experiments, considering the same range of temperature (result not shown). The evaporation process for PTCD derivatives is carried out at temperatures below $400^{\circ} \mathrm{C}^{31}$. Therefore, neither phase transition events nor thermal degradation would prevent the preparation of BuPTCD films by PVD.

The growth of PVD films of BuPTCD with 20, 40, 60,80 , and $100 \mathrm{~nm}$ was monitored by UV-Vis absorption spectroscopy, as shown in Figure 2. The linear dependence of the absorbance at $465 \mathrm{~nm}$ (inset A in Figure 2) indicates that similar amounts of material are deposited onto the substrate at each evaporation step, revealing a controlled growth of the PVD films.

The UV-Vis absorption spectra of perylene derivatives usually consist of electronic transitions with characteristic vibronic structures ${ }^{32,33}$. For instance, the inset B in Figure 2 shows the UV-Vis absorption spectra for both BuPTCD solution $\left(10^{-6} \mathrm{~mol} / \mathrm{L}\right)$ and PVD film $(100 \mathrm{~nm})$. The solution spectrum displays three main absorption bands associated with $\pi-\pi^{*}$ transition of the perylene chromophore: $0-0$, 0-1 and 0-2 transitions with maxima at 523, 486 and 455, respectively. The absorption spectrum of the PVD film shows an intense blue-shift component with a broad maximum at $463 \mathrm{~nm}$ and a red-shift component at $573 \mathrm{~nm}$. Applying the Kasha's point-dipole model, ${ }^{34}$ the red-shift band could be related to "head-to-tail" arrangement of the dipoles (J-aggregates) and the blue-shift band to the "card pack" arrangement of the dipoles (H-aggregates). Therefore, the strong red- and blue-shift band components observed in the UV-Vis absorption spectra of the PVD film point out for an intermediate case with coexistent $\mathrm{J}$ and $\mathrm{H}$ molecular aggregates. The latter suggests that BuPTCD molecules may be arranged on top of each other, forming a multilayer 


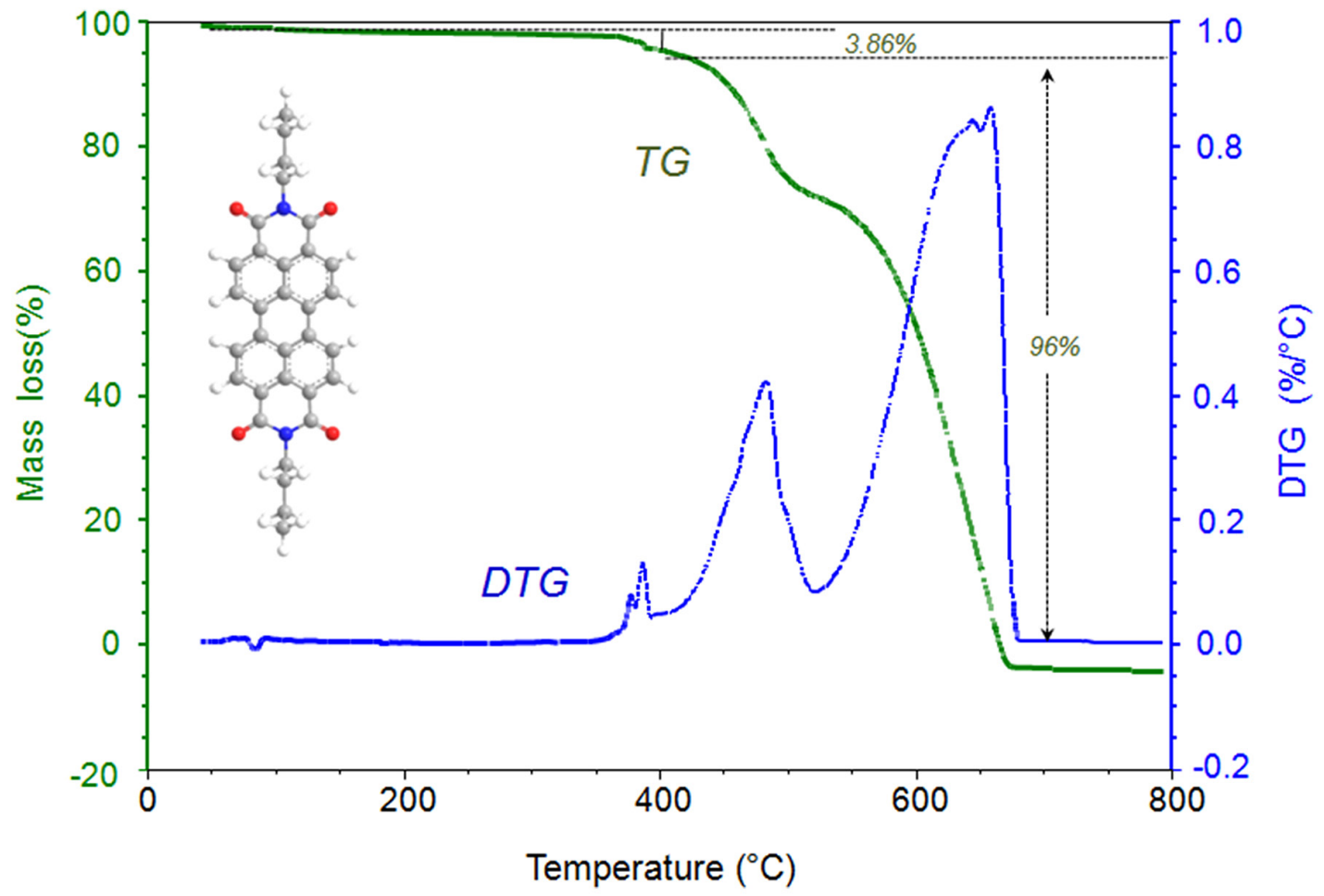

Figure 1. TG and DTG curves for BuPTCD powder from $25^{\circ} \mathrm{C}$ to $800^{\circ} \mathrm{C}$ (heating rate of $10^{\circ} \mathrm{C} / \mathrm{min}$ ). Inset: BuPTCD molecular structure.

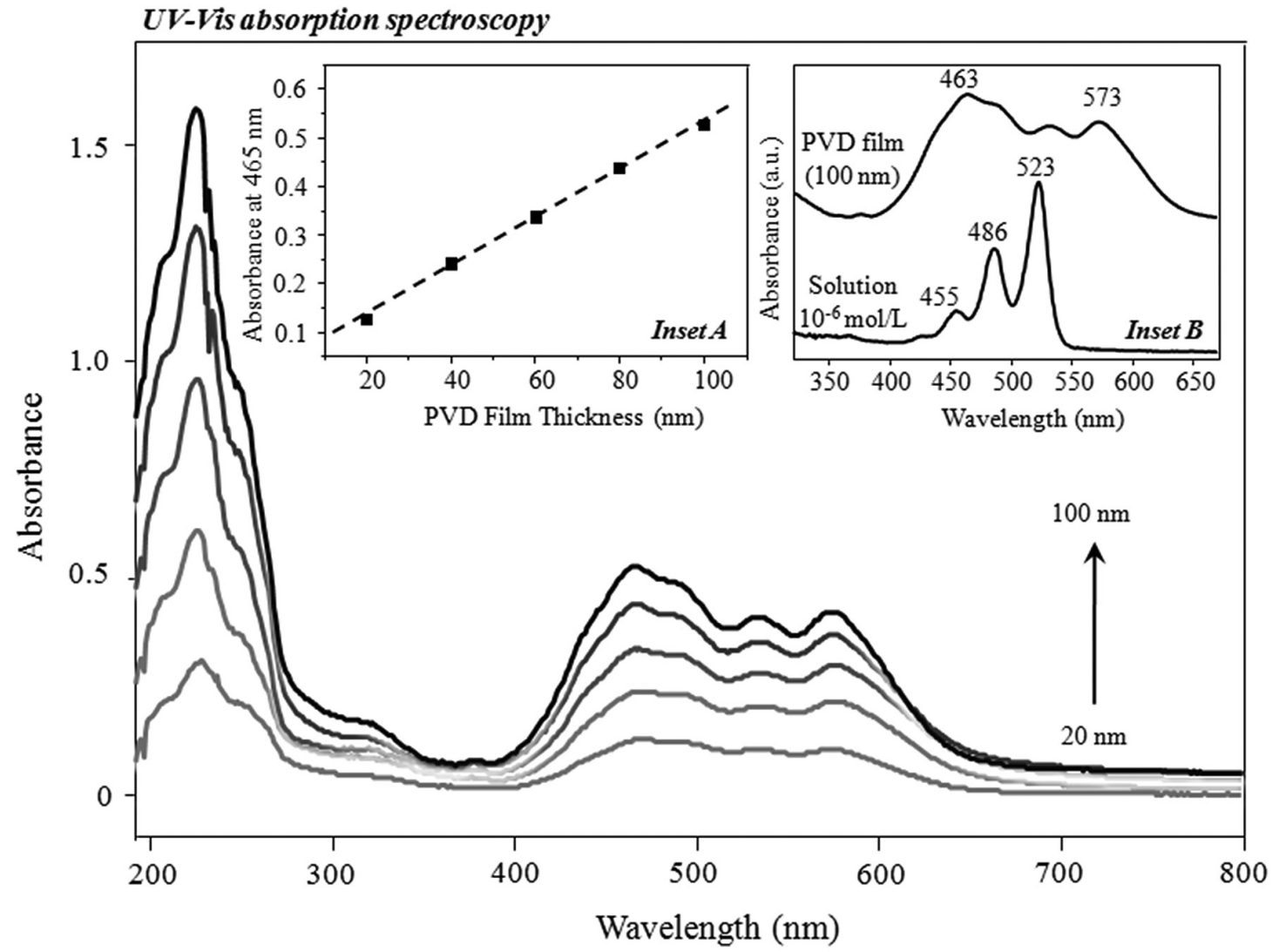

Figure 2. UV-Vis absorption spectra for BuPTCD PVD films with 20, 40, 60, 80, and $100 \mathrm{~nm}$. The insets show (A) the absorbance at 465 $\mathrm{nm}$ for each evaporation step and (B) the absorption spectra for both BuPTCD solution $\left(10^{-6} \mathrm{~mol} / \mathrm{L}\right)$ and PVD film $(100 \mathrm{~nm})$. 
with $\mathrm{H}$ and $\mathrm{J}$ molecular aggregates, similar to observed for a different perylene derivative (bis benzimidazo perylene, AzoPTCD) when forming PVD films ${ }^{31}$.

Figure 3 a shows a photograph of the $100 \mathrm{~nm}$ BuPTCD PVD film taken with a digital camera. An optical image with $500 \times$ magnification for the same film is shown in Figure $3 b$, revealing a highly homogeneous and smooth film surface at the microscale. The PVD film morphology at nanometer scale was determined by AFM, shown in Figure 3c. The AFM images also reveal a smooth surface, indicating that the homogeneous morphological pattern observed at micrometer scale is kept at nanometer scale.

The BuPTCD PVD film was also characterized in terms of RMS roughness and average height, calculated by the standard deviation according to the Equation 1:

$$
R_{r m s}=\sqrt{\frac{\sum_{n=l}^{N}\left(Z_{n}-\bar{Z}\right)^{2}}{N-1}}
$$

is the average of $Z$ values in the determined area, $Z n$ is the height of the $\mathrm{n}^{\text {th }}$ pixel, $N$ is the number of pixels considered in the determined area and the average height is simply the arithmetic average of the measured heights. The values of roughness and average height are obtained for areas of $30 \mu \mathrm{m} \times 30 \mu \mathrm{m}, 20 \mu \mathrm{m} \times 20 \mu \mathrm{m}$ and $10 \mu \mathrm{m} \times 10 \mu \mathrm{m}$ and are shown in Table 1.

The high homogeneity of the PVD film is evidenced by the low values of RMS roughness and average height in relation to the film thickness, being nearly constant for the different scanned areas. The PVD film thickness was also evaluated by AFM. Figure 4 shows the surface profile produced by scratching the PVD film, revealing a thickness of ca. $100 \mathrm{~nm}$. Once again the PVD film homogeneity is highlighted by the low values of RMS roughness, which was found to be less than ca.3\% of the film thickness. Volpati et al. ${ }^{31}$ have shown that depending on the experimental conditions, PVD films of AzoPTCD may reach different values of RMS roughness, varying from 5 to $15 \%$ of the film thickness. Ferguson \& Jones ${ }^{35}$ working with PVD films of 3,4,9,10-perylenetetracarboxylicdianhydride (PTCDA) found RMS roughness of ca. $2.77 \%$ in relation to the film thickness, similar to the results present here, revealing the suitability of the PVD technique.

\subsection{BUPTCD PVD film: molecular organization and crystallinity}

FTIR measurements were recorded in order to probe the PVD film anisotropy. The molecular organization of BuPTCD molecules is investigated by comparing the transmission and reflection FTIR spectra, shown in Figure 5. The transmission FTIR spectrum of BuPTCD powder dispersed in $\mathrm{KBr}$ pellet is considered to be the reference for a system with random molecular organization. The differences found in relative intensities of the powder and PVD film (transmission mode), besides the differences in relative intensities of the PVD film spectra (transmission and reflection modes), suggest a strong anisotropy in terms of molecular organization. The determination of the molecular orientation can be performed by combining FTIR data and selection rules, described briefly as follows ${ }^{36-38}$.

(i) The incident electric field of the infrared radiation is parallel to the substrate surface in the transmission mode $\left(\mathrm{E}_{/ /}\right)$, Figure $6 \mathrm{a}$.

(ii) Considering the metal used ( $\mathrm{Ag})$ and the incident angle $\left(80^{\circ}\right)$, the electric field is polarized perpendicular to the substrate surface in the reflection mode $\left(E_{\perp}\right)$, Figure $6 b$.

(iii) The intensity of the infrared absorption (I) depends on the interaction between the electric field of the incident radiation $(\mathrm{E})$ and the variation of the molecular dipole moment $(\mu)$ following the scalar product $I=\vec{E} \cdot \vec{\mu}$.

Table 1. roughness (RMS) and average height for $100 \mathrm{~nm}$ PVD film of BuPTCD

\begin{tabular}{cccc}
\hline Sample & $\begin{array}{c}\text { Area } \\
\left(\boldsymbol{\mu \mathbf { m } ^ { 2 } )}\right.\end{array}$ & $\begin{array}{c}\text { RMS } \\
\text { roughness } \\
(\mathbf{n m})\end{array}$ & $\begin{array}{c}\text { Average } \\
\text { height } \\
(\mathbf{n m})\end{array}$ \\
\hline & $30 \times 30$ & 2.55 & 1.9 \\
BuPTCD & $20 \times 20$ & 2.53 & 1.9 \\
PVD film & $10 \times 10$ & 2.48 & 1.8 \\
\hline
\end{tabular}

(a) Photo

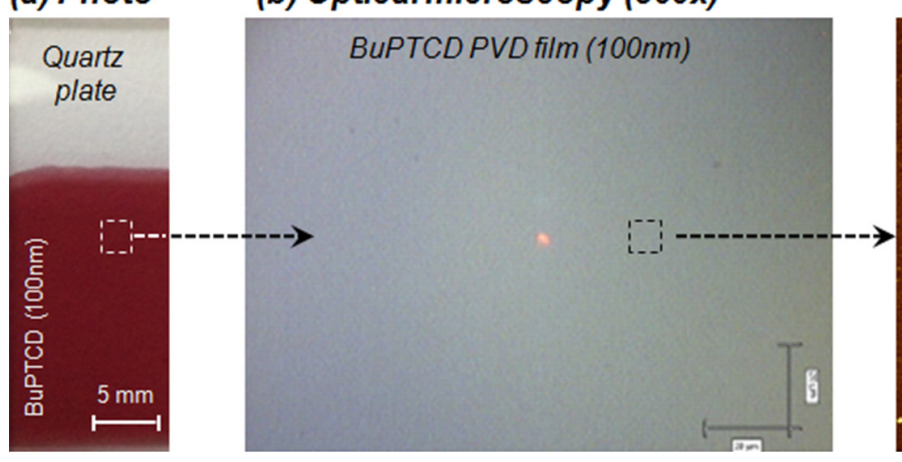

(c) Atomic force microscopy (AFM)

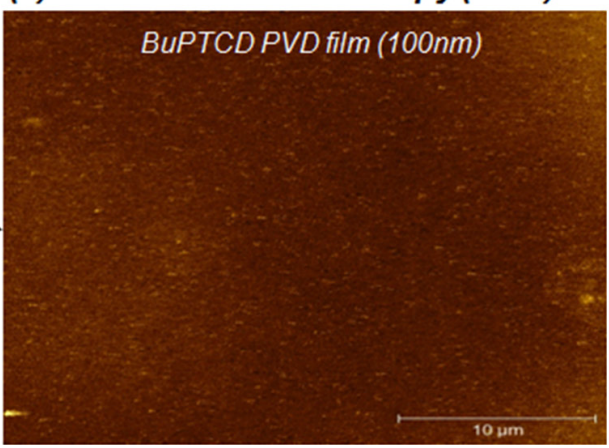

Figure 3. (a) Photograph obtained with a digital camera, (b) optical microscopy with $500 \times$ magnification, and (c) atomic force microscopy (AFM, topography) for the $100 \mathrm{~nm}$ PVD film deposited onto quartz plate. 
Considering that the polarization of the electric field of the incident radiation is known, the molecular organization can be determined using FTIR bands which $\mu$ components are well established in relation to the molecule symmetry. For instance, considering the PVD film spectra (transmission and reflection modes), significant differences in terms of band relative intensities are found at 1697 and $1660 \mathrm{~cm}^{-1}$ assigned to $\mathrm{C}=\mathrm{O}$ symmetric and antisymmetric stretching, respectively ${ }^{39}$. Such vibrational modes are associated with dipole moments that lie on the plane of the chromophore. Considering the antisymmetric $\left(1660 \mathrm{~cm}^{-1}\right)$ and symmetric $\left(1697 \mathrm{~cm}^{-1}\right)$ stretching modes, the resulting dipole components are parallel and perpendicular to the short axis of the chromophore, respectively (Figure 6). Another important change in relative intensity is observed for the absorption bands at 809 and $745 \mathrm{~cm}^{-1}$, both assigned to $\mathrm{C}-\mathrm{H}$ wagging, a dihedral angular deformation, out of the plane modes of the chromophore (Figure 6) ${ }^{40,41}$. These resultant dipole moments and the polarization of the incident electric field (transmission and reflection) modes are illustrated in Figure $6 a$ and $6 b$, respectively.

The higher relative intensity of the band at $809 \mathrm{~cm}^{-1}$ (C-H wagging) in transmission mode for PVD film (Figure 5) points out to a preferential orientation of the molecule with the plane of the chromophore perpendicular to the substrate. However, it is not possible to infer whether the molecule is standing head-on (short axis of the chromophore, with the alkyl chain touching the substrate surface) or side-on (long
AFM - BUPTCD PVD film (100nm)
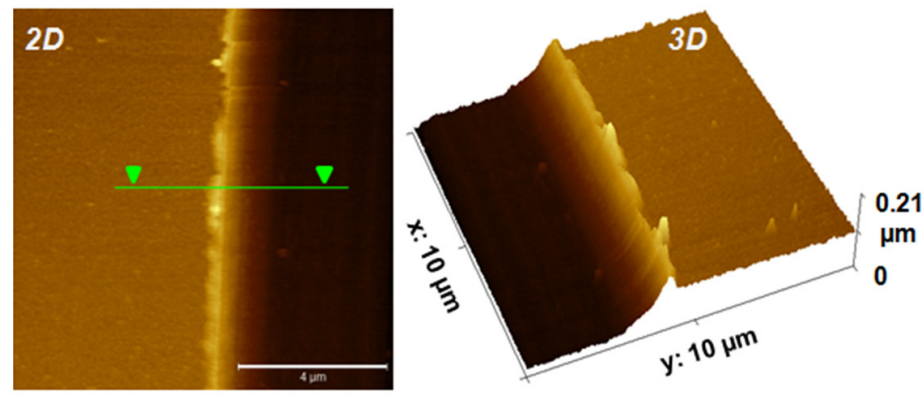

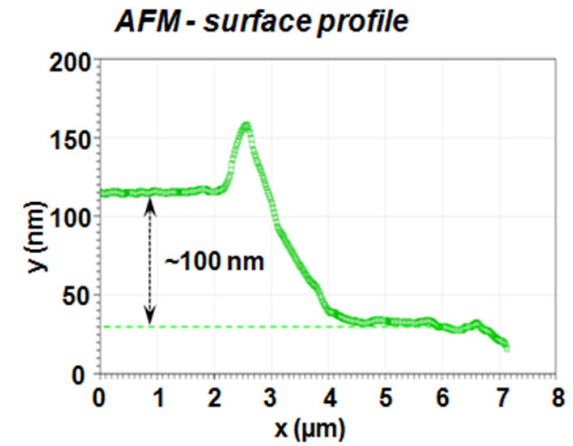

Figure 4. Topographic AFM images (2D and 3D) showing the profile along an edge, made by scratching the $100 \mathrm{~nm}$ PVD film of BuPTCD.

FTIR

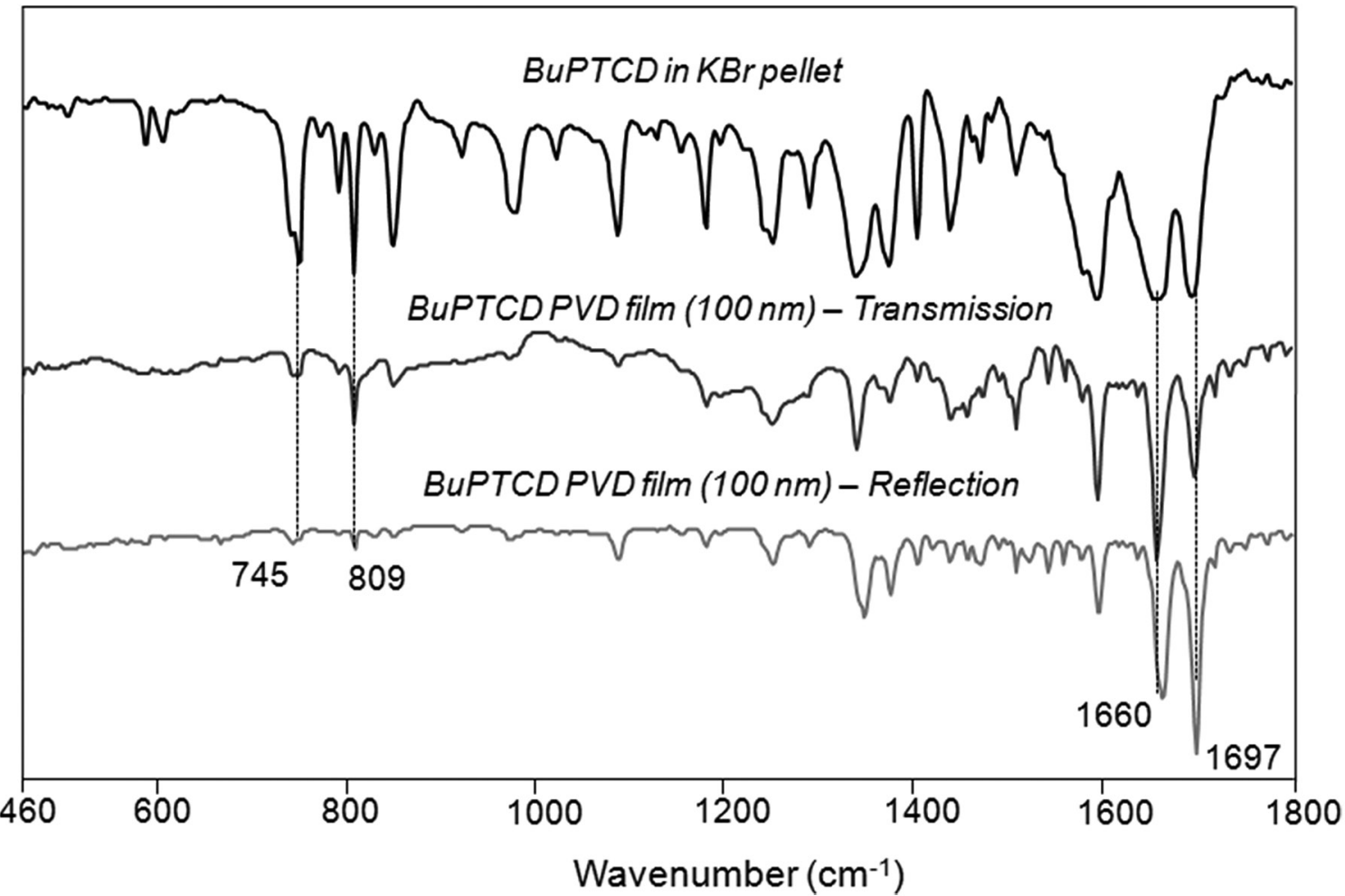

Figure 5. FTIR spectra recorded from BuPTCD powder dispersed in $\mathrm{KBr}$ pellet and $100 \mathrm{~nm}$ PVD film deposited simultaneously onto Ge (transmission mode) and $\mathrm{Ag}$ mirror (reflection mode). 
axis of the chromophore touching the substrate surface). The higher intensity of the band at $1660 \mathrm{~cm}^{-1}\left(\mathrm{C}=\mathrm{O}_{\text {antsym }}\right)$ in transmission mode for PVD film (Figure 5) suggests that the molecule is standing head-on. In addition, the higher intensity of the band at $1697 \mathrm{~cm}^{-1}\left(\mathrm{C}=\mathrm{O}_{\text {sym }}\right)$ in reflection mode for PVD film (Figure 5) confirms this hypothesis. Therefore, BuPTCD molecules are preferentially orientated with the plane of the chromophore perpendicular to the substrate, standing head-on, as depicted in Figure 6c. Antunes et al. ${ }^{41}$ have found similar molecular orientation for PVD films of perylene tetracarboxylic derivatives (PTCDs) with alkyl lateral chains with different lengths $(5,10,15$, and 20 carbons). The authors highlighted that the larger alkyl lateral chains the more tilted the molecules in relation to the normal of the substrate surface. Furthermore, by changing the composition of lateral groups attached to the chromophore, different molecular orientation may be reached, as verified by Volpati et al. ${ }^{31}$ working with PVD films of AzoPTCD.

In addition, polarized FTIR measurements with $0^{\circ}, 30^{\circ}$, $60^{\circ}$ and $90^{\circ}$ were performed in transmission mode. The goal is to figure out whether the plane of the molecule displays a preferential orientation in $\mathrm{X}$ or $\mathrm{Z}$ directions (Figure $6 \mathrm{c}$ ). Significant changes were not observed on the FTIR spectra, with respect to the polarization angle, as shown in the Appendix (Figure 1S). The latter suggests that, besides the head-on molecular organization (Figure $6 \mathrm{c}$ ) in Y direction, the molecule presents a random orientation in $\mathrm{X}$ or $\mathrm{Z}$ directions, as further discussed by the X-ray data (inset in Figure 7).
Finally, the $100 \mathrm{~nm}$ BuPTCD film was probed upon annealing up to $200^{\circ} \mathrm{C}$ at environmental atmosphere for $2 \mathrm{~h}$. The main objective is to determine the effect of annealing on the film molecular organization. The FTIR spectra recorded after annealing (Appendix Figure 2S) have proven to be very similar to the FTIR spectra (reflection mode) taken before heating. Therefore, the BuPTCD PVD film does not change its molecular organization under the thermal treatment applied here, indicating a thermal stability for this range of temperature. Changes in the molecular organization due to annealing can be reached for PTCD derivatives with smaller (propyl) lateral groups, as reported by Kam et al. ${ }^{42}$

Figure 7 shows the X-ray diffraction patterns of powder and $100 \mathrm{~nm}$ PVD film evaporated onto quartz. The well-defined crystalline structure in a single crystallographic plane observed for the PVD film indicates that BuPTCD molecules have a preferred orientation along the film. According to Hädicke \& Graser, ${ }^{43}$ the crystal structure of BuPTCD is monoclinic with lattice parameters: $\mathrm{a}=0.4734, \mathrm{~b}=2.8233, \mathrm{c}=0.9396 \mathrm{~nm}$, $\beta=110.86^{\circ}$. The intense peak at $6.25^{\circ}(2 \theta)$ indicates that the crystalline film deposited on the substrate is oriented parallel to the sample (020) crystalline plane. Therefore, one can assume that molecular plane of BuPTCD stands obliquely to the surface, with the peripheral butyl groups alternately bounded to the peryleneskeleton, ${ }^{43,44}$ as depicted on the inset in Figure 7. In a similar approach Yanagi et al. ${ }^{44}$ have found similar results controlling the orientation of perylene (a)

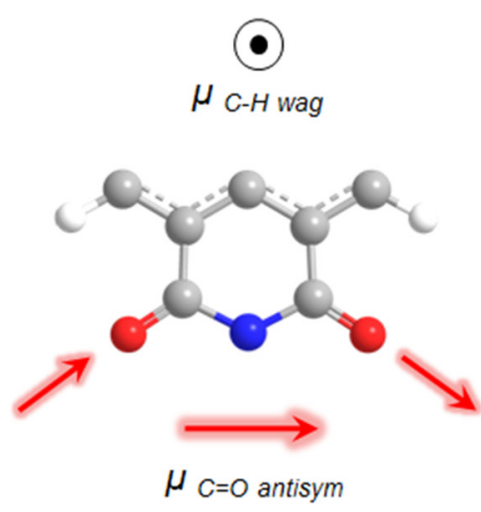

Transmission

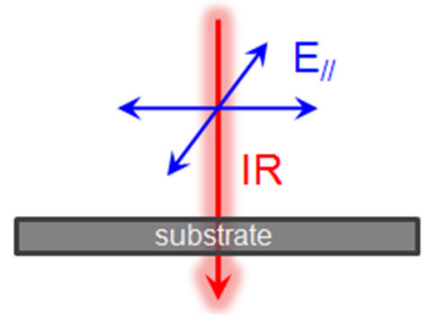

(b)

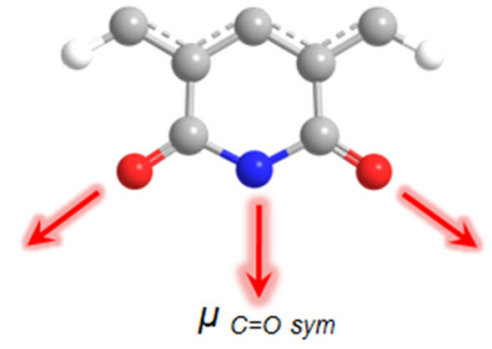

Reflection

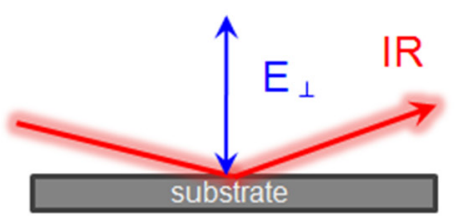

(c)

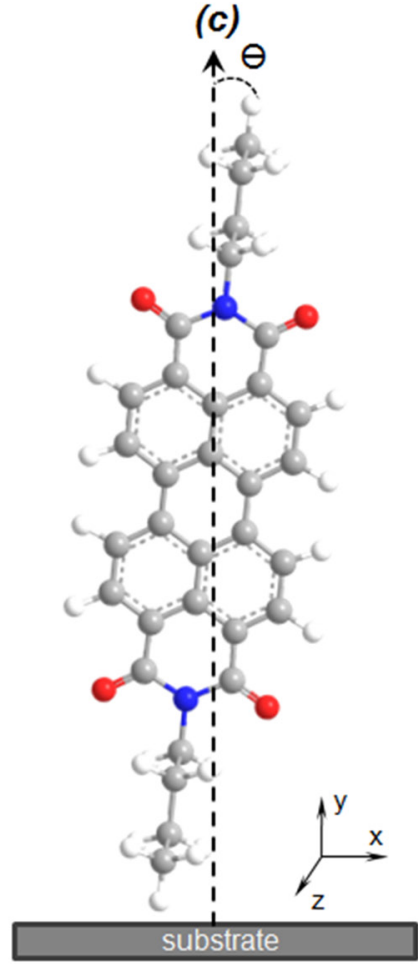

Figure 6. Resultant dipole moments $(\mu)$ and polarization of the incident electric field on (a) transmission and (b) reflection modes. (c) Scheme of molecular organization proposed for BuPTCD in PVD films. 


\section{$X$-ray diffraction}

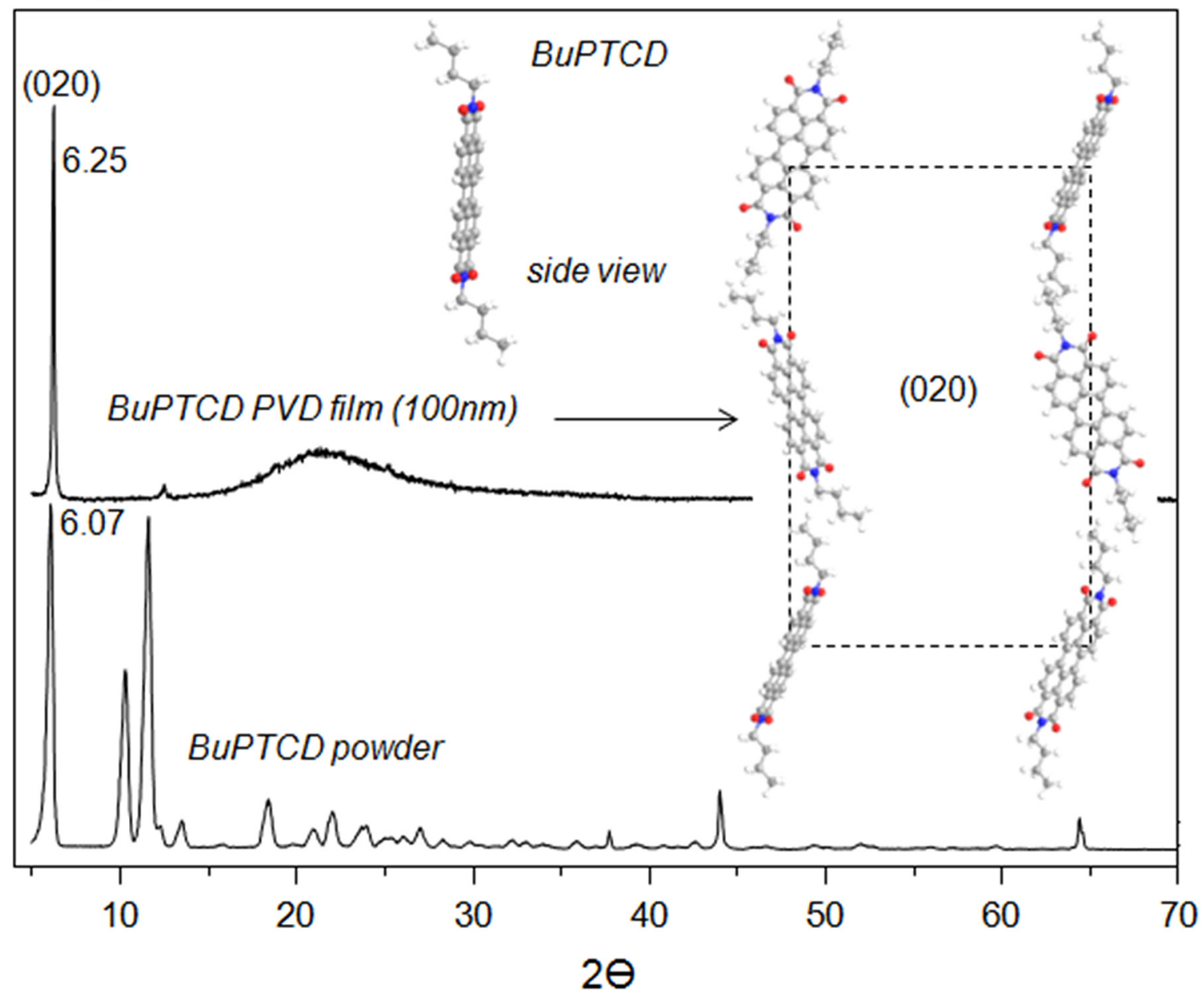

Figure 7. X-ray diffractograms for BuPTCD powder and $100 \mathrm{~nm}$ PVD film. The inset depicts the BuPTCD preferential organization in PVD films.

derivatives in evaporated thin films for photoelectrochemical measurements.

\subsection{Electrical properties - DC measurements}

The electrical conductivity for $100 \mathrm{~nm}$ PVD film of BuPTCD deposited onto Au interdigitated electrodes (IDE - inset in Figure 8a) is determined by current vs. voltage curves (I vs. V), performed in dark environment and displayed in Figure 8a. The increase in current as a function of the DC voltage follows a linear relation, characteristic of ohmic behavior ${ }^{45}$. The film resistance can be extracted from the fittings of I vs. V curves, following the simple relation: $y=a+b x$ where the curve slope $\left(\mathrm{b}=1.46 \times 10^{-10} \mathrm{~S}\right)$ is physically assigned to $\frac{1}{R}$. Using a model from Olthuis et al. ${ }^{46}$, the conductivity of the IDE-structured device is obtained from its resistance considering the IDE cell constant, estimated to be $5.1 \mathrm{~m}^{-1}$ in our case. ${ }^{47}$ Therefore, the electrical conductivity of BuPTCD PVD film is estimated in ca. $7.45 \times 10^{-10} \mathrm{~S} / \mathrm{m}$. The same IDE-structured device electrodes were used for photoconductivity measurements. An enhancement of the electrical current is observed under illumination with halogen lamp $\left(\sim 150 \mathrm{~mW} / \mathrm{cm}^{2}\right)$, as shown by I vs. $t$ curve (applied voltage $5 \mathrm{~V}$ ) in Figure $8 \mathrm{~b}$. The photoconduction effect is clear, since the electrical current increases by about 2 orders of magnitude, from $4.3 \times 10^{-10}$ to $1.8 \times 10^{-8} \mathrm{~A}$. The conductivity value and the photoconduction effect are in agreement with what Tkachenko et al. ${ }^{48}$ have found for PVD films of perylene tetracarboxylic diimide (PTCDI), which have carried out a detailed and extensively work for ten distinct molecules: Alq3 (tris-(8-hydroxyquinoline) aluminum), BCP (2,9-dimethyl-4,7-diphenyl-1,10phenanthroline), $\mathrm{CuPc}$ (copper(II) phthalocyanine), fullerene C60, PTCDI (3,4,9,10-perylenetetracarboxylicdiimide), PHT (regioregular poly(3-hexylthiophene), DHD6ee and TBD6a (porphyrin-fullerene dyads), ZnBTZ and 3TCNS. According to the authors ${ }^{48}$, "The best n-type conducting material is PTCDI, and it has shown the highest (hundred times) decrease in resistivity under the light illumination."

The BuPTCD film in IDE-structured device was considered as a TFA gas sensor using I vs. t measurements (applied voltage $5 \mathrm{~V}$ ), as shown in Figure 9. The current, and consequently, 
(a) I vs. V

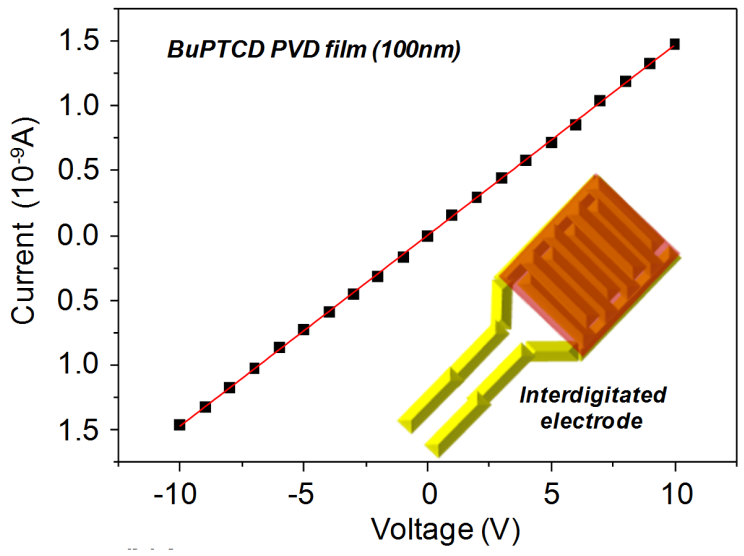

(b) I vs. $t$

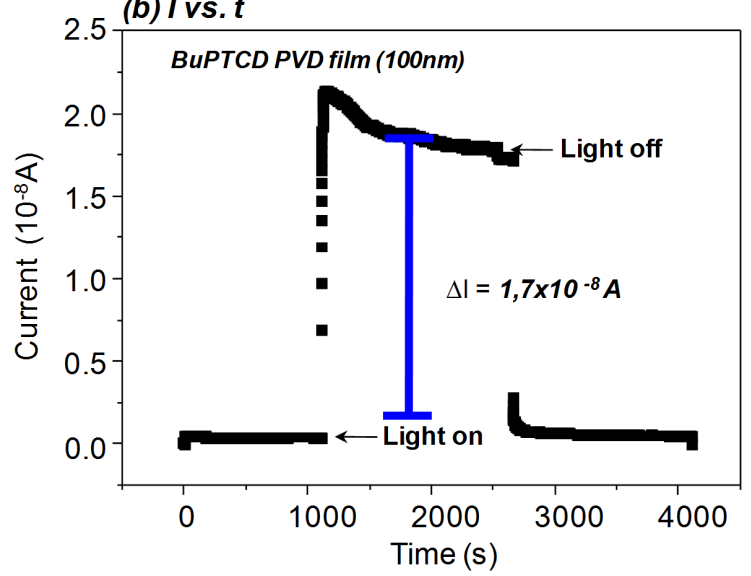

Figure 8. (a) I vs. V curve for the $100 \mathrm{~nm}$ PVD film of BuPTCD deposited onto Au interdigitated electrodes. The inset depicts the $\mathrm{Au}$ interdigitated electrode covered by BuPTCD PVD film. (b) I vs. t curve for the $100 \mathrm{~nm}$ PVD film of BuPTCD deposited onto Au interdigitated electrodes when irradiated with a halogen lamp at $150 \mathrm{~mW} / \mathrm{cm}^{2}$.

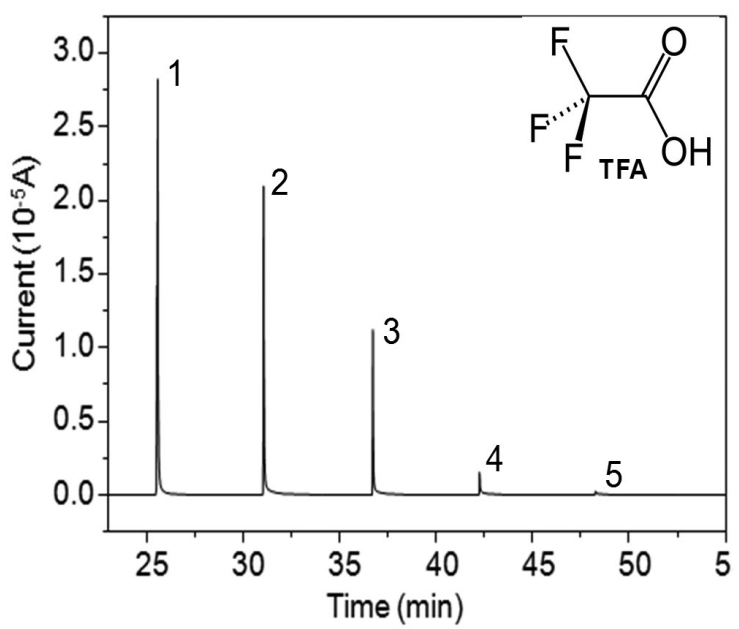

(a)

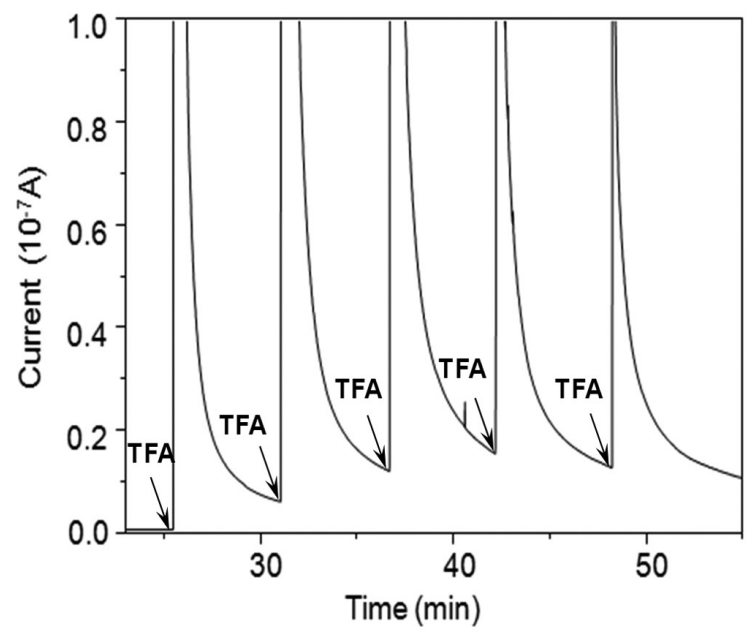

(b)

Figure 9. (a) Increase and decrease of the current as a function of TFA injections (5 injections). Inset: TFA molecular structure. (b) Zoom for lower current values of the curves shown in (a).

the electrical conductivity increased as the TFA gas was injected, although the relative response intensity decreased from the first to the last syringe. According to S. Ji et al. ${ }^{49}$, this response decrease may be assigned to the saturation of the surface area. From the literature, the sensitivity of organic semiconducting materials as gas sensor units is related to the surface area that can provide the diffusion of the analyte molecules ${ }^{50,51}$ and the chemical nature of the semiconducting materials, such as redox potentials, which are associated with the formation of charge carriers and its efficient transport through the materials ${ }^{52}$. In our case, specifically, BuPTCD protonation under TFA exposition must be considered. Another point to be taken into account is the interplanar spacing between perylene core, which is crucial for efficient carrier transport, and therefore $\pi-\pi$ stacking distance may play a critical role in the sensing performance of perylene derivatives ${ }^{53}$. In summary, the BuPTCD PVD film shows fast response toward TFA gas, probably due to protonation (mainly at the surface film), associated with the $\pi-\pi$ stacking in a packed structure that favors the charge carrier mobility ${ }^{54}$.

\section{Conclusion}

Thin films of bis butylimido perylene (BuPTCD) were successfully produced by the physical vapor deposition (PVD) technique. The thermogravimetric analysis and vibrational spectroscopy ensures that the molecule is not degraded during the deposition process. A smooth and homogeneous surface at nano and micrometer scales is found with roughness around $3 \%$ in relation to the thickness of the film. The X-ray diffraction data reveal a well-defined crystalline structure in a single crystallographic plane, pointing out for preferential orientation of BuPTCD molecules within the PVD film. The latter is confirmed considering both FTIR results (transmission and reflection modes) and surface selection rules, being BuPTCD 
molecules preferentially orientated head-on with the plane of the chromophore almost perpendicular to the substrate plane. This molecular organization was not affected by the annealing process $\left(200^{\circ} \mathrm{C}\right)$. The DC electrical analysis shows a conductivity of $4.3 \times 10^{-10} \mathrm{~S} / \mathrm{m}$ for the BuPTCD onto IDE structure. In the same structure the photovoltaic effect was observed, and the electrical current enhanced about 2 orders of magnitude (from $4.3 \times 10^{-10}$ to $1.8 \times 10^{-8} \mathrm{~A}$ )

\section{References}

1. Guo X, Baumgarten M and Muellen K. Designing $\pi$-conjugated polymers for organic electronics. Progress in Polymer Science. 2013; 38(12):1832-1908. http://dx.doi.org/10.1016/j. progpolymsci.2013.09.005.

2. Schlettwein D, Back A, Schilling B, Fritz T and Armstrong NR. Ultrathin films of perylenedianhydride and perylenebis(dicarboximide) dyes on (001) alkali halide surfaces. Chemistry of Materials. 1998; 10(2):601-612. http://dx.doi.org/10.1021/cm970589+.

3. Ivri J, Burshtein Z, Miron E, Reisfeld R and Eyal M. The perylene derivative BASF-241 solution as a new tunable dye laser in the visible. IEEE Journal of Quantum Electronics. 1990; 26(9):1516-1520. http://dx.doi.org/10.1109/3.102629.

4. Lohmannsroben HG and Langhals H. Laser performance of perylenebis (dicarboximide) dyes with long secondary alkyl chains. Applied Physics B: Photophysics and Laser Chemistry. 1989; 48:449-452. http://dx.doi.org/10.1007/BF00694678.

5. Horowitz G, Kouki F, Spearman P, Fichou D, Nogues C, Pan X, et al. Evidence for n-type conduction in a perylene tetracarboxylic diimide derivative. Advanced Materials. 1996; 8(3):242-245. http://dx.doi.org/10.1002/adma.19960080312.

6. Langhals H. Dyes with high dielectric constants. Chemical Physics Letters. 1988; 150(3-4):321-324. http://dx.doi. org/10.1016/0009-2614(88)80050-2.

7. Li H, Li J, Xu Q, Yang Z and Hu X. A derivative photoelectrochemical sensing platform for 4-nitrophenolate contained organophosphates pesticide based on carboxylated perylene sensitized nanoTiO2. Analytica Chimica Acta. 2013; 766:47-52. http://dx.doi. org/10.1016/j.aca.2012.12.038. PMid:23427799.

8. Kozma E and Catellani M. Perylene diimides based materials for organic solar cells. Dyes and Pigments. 2013; 98(1):160179. http://dx.doi.org/10.1016/j.dyepig.2013.01.020.

9. Chu X, Guan M, Zhang Y, Li Y, Liu X, Zhu Z, et al. Influences of organic-inorganic interfacial properties on the performance of a hybrid near-infrared optical upconverter. RSC Advances. 2013; 3(45):23503-23507. http://dx.doi.org/10.1039/c3ra43143f.

10. Keil C, Graaf H, Baumgaertel T, Trenkmann I and Schlettwein D. Intralayer vs. interlayer electronic coupling in perylene imide thin films. Organic Electronics. 2013; 14(11):2833-2839. http:// dx.doi.org/10.1016/j.orgel.2013.07.030.

11. Niu X, Yang W, Guo H, Ren J and Gao J. Highly sensitive and selective dopamine biosensor based on 3,4,9,10-perylene tetracarboxylic acid functionalized graphene sheets/multi-wall carbon nanotubes/ionic liquid composite film modified electrode. Biosensors \& Bioelectronics. 2013; 41:225-231. http://dx.doi. org/10.1016/j.bios.2012.08.025. PMid:22951031.

12. L. Zhong, F. Xing, Y. Bai, Y. Zhao and S. Zhu. Aspartic acid functionalized water-soluble perylene diimide as "Off-On" fluorescent sensor for selective detection $\mathrm{Cu} 2+$ and ATP. Spectrochimica Acta Part A: Molecular and Biomolecular Spectroscopy, 2013; 115:370-375. upon illumination. As proof-of-concept, it is shown that the BuPTCD has a fast DC electrical response toward TFA gas, revealing its potential to be applied as gas sensor.

\section{Acknowledgements}

FAPESP, CNPq and CAPES for the financial support and LMF (LNNano-LNLS) for the interdigitated electrodes.

13. Ramesh M, Lin H-C and Chu C-W. Organic thin film transistors as selective sensing platforms for $\mathrm{Hg}^{2+}$ ions and the amino acid cysteine. Biosensors \& Bioelectronics. 2013; 42:76-79. http:// dx.doi.org/10.1016/j.bios.2012.10.050. PMid:23202334.

14. Nakahara H, Hirano C, Fujita I and Shibata O. Interfacial properties in Langmuir monolayers and LB films of DPPC with partially fluorinated alcohol $(\mathrm{F} 8 \mathrm{H} 7 \mathrm{OH})$. Journal of Oleo Science. 2013; 62(12):1017-1027. http://dx.doi.org/10.5650/ jos.62.1017. PMid:24292354.

15. Song J, Tian Q, Gao J, Wu H, Chen Y and Li X. Controlled preparation of CdS nanoparticle arrays in amphiphilic perylene tetracarboxylic diimides: organization, electron-transfer and semiconducting properties. CrystEngComm. 2014; 16(7):12771286. http://dx.doi.org/10.1039/c3ce41977k.

16. Lee SH, Jamison AC, Hoffman DM, Jacobson AJ and Lee TR. Preparation and characterization of polymeric thin films containing gold nanoshells via electrostatic layer-by-layer self-assembly. Thin Solid Films. 2014; 558:200-207. http:// dx.doi.org/10.1016/j.tsf.2014.02.021.

17. Bauman D, Hertmanowski R, Stefanska K and Stolarski R. The synthesis of novel perylene-like dyes and their aggregation properties in Langmuir and Langmuir-Blodgett films. Dyes and Pigments. 2011; 91(3):474-480. http://dx.doi.org/10.1016/j. dyepig.2011.03.032.

18. Chen Q, Worfolk BJ, Hauger TC, Al-Atar U, Harris KD and Buriak JM. Finely tailored performance of inverted organic photovoltaics through layer-by-layer interfacial engineering. ACS Applied Materials \& Interfaces. 2011; 3(10):3962-3970. http://dx.doi.org/10.1021/am200849r. PMid:21950539.

19. Tippo T, Thanachayanont C, Muthitamongkol P, Junin C, Hietschold $\mathrm{M}$ and Thanachayanont A. The effects of solvents on the properties of ultra-thin poly (methyl methacrylate) films prepared by spin coating. Thin Solid Films. 2013; 546:180-184. http://dx.doi.org/10.1016/j.tsf.2013.05.022.

20. Mao L-K, Gan J-Y, Hwang J-C, Chang T-H and Chueh Y-L. The role of water in the device performance of n-type PTCDI-C8 organic field-effect transistors with solution-based gelatin dielectric. Organic Electronics. 2014; 15(4):920-925. http:// dx.doi.org/10.1016/j.orgel.2014.01.023.

21. Luo L, Bozyigit D, Wood V and Niederberger M. High-quality transparent electrodes spin-cast from preformed antimony-doped tin oxide nanocrystals for thin film optoelectronics. Chemistry of Materials. 2013; 25(24):4901-4907. http://dx.doi.org/10.1021/ cm4030149.

22. Ito F, Kogasaka Y and Yamamoto K. Fluorescence spectral changes of perylene in polymer matrices during the solvent evaporation process. The Journal of Physical Chemistry B. 2013; 117(13):3675-3681. http://dx.doi.org/10.1021/jp401002y. PMid:23527959.

23. Sanchez-Vergara ME, Rivera M, Alonso-Huitron JC, Rodriguez A and Alvarez-Bada JR. Electrical and optical properties of coppercomplexes thin films grown by the vacuum thermal evaporation technique. Materials Chemistry and Physics. 2013; 138(1):392398. http://dx.doi.org/10.1016/j.matchemphys.2012.11.072. 
24. Vasseur K, Rolin C, Vandezande S, Temst K, Froyen L and Heremans P. A growth and morphology study of organic vapor phase deposited perylene diimide thin films for transistor applications. The Journal of Physical Chemistry C. 2010; 114(6):2730-2737. http://dx.doi.org/10.1021/jp909242n.

25. Ali M, Syed WAA, Zubair M, Shah NA and Mehmood A. Physical properties of Sb-doped CdSe thin films by thermal evaporation method. Applied Surface Science. 2013; 284:482488. http://dx.doi.org/10.1016/j.apsusc.2013.07.122.

26. Rebarz M, Wojdyla M, Bala W and Lukasiak Z. Study of excited states in thin films of perylene derivatives by photoluminescence and absorption spectroscopy. Optical Materials. 2008; 30(5):774776. http://dx.doi.org/10.1016/j.optmat.2007.02.035.

27. Xing X, Zhong L, Zhang L, Chen Z, Qu B, Chen E, et al. Essential differences of organic films at the molecular level via vacuum deposition and solution processes for organic lightemitting diodes. The Journal of Physical Chemistry C. 2013; 117(48):25405-25408. http://dx.doi.org/10.1021/jp410547w.

28. Hofmockel R, Zschieschang U, Kraft U, Roedel R, Hansen NH, Stolte M, et al. High-mobility organic thin-film transistors based on a small-molecule semiconductor deposited in vacuum and by solution shearing. Organic Electronics. 2013; 14(12):32133221. http://dx.doi.org/10.1016/j.orgel.2013.09.003.

29. Greenler RG. Infrared study of adsorbed molecules on metal surfaces by reflection techniques. The Journal of Chemical Physics. 1966; 44(1):310-315. http://dx.doi.org/10.1063/1.1726462.

30. Moskovits M. Surface selection rules. The Journal of Chemical Physics. 1982; 77(9):4408-4416. http://dx.doi.org/10.1063/1.444442.

31. Volpati D, Job AE, Aroca RF and Constantino CJL. Molecular and morphological characterization of bis benzimidazo perylene films and surface-enhanced phenomena. The Journal of Physical Chemistry B. 2008; 112(13):3894-3902. http://dx.doi.org/10.1021/ jp077588h. PMid:18335918.

32. Mercadante R, Trsic M, Duff J and Aroca R. Molecular orbital calculations of perylenetetracarboxylic monoimide and bisimide. Alkyl derivatives and heteroatom analogs. Journal of Molecular Structure: THEOCHEM. 1997; 394:215-226. http://dx.doi. org/10.1016/S0166-1280(96)04837-3.

33. Aroca RF and Constantino CJL. Surface-enhanced raman scattering: imaging and mapping of Langmuir-Blodgett monolayers physically adsorbed onto silver island films. Langmuir. 2000; 16(12):5425-5429. http://dx.doi.org/10.1021/ la991478n.

34. Ramamurthy V, editor. Photochemistry in organized and constrained media. In: Spooner SP and Whitten DG. Photoreactions in monolayer films and Langmuir-Blodgett assemblies. New York: VCH Publishers; 1991. Chap. 15. p. 691-738.

35. Ferguson AJ and Jones TS. Photophysics of PTCDA and MePTCDI thin films: effects of growth temperature. The Journal of Physical Chemistry B. 2006; 110(13):6891-6898. http:// dx.doi.org/10.1021/jp056899u. PMid:16570999.

36. Bradshaw AM and Schweizer E. Spectroscopy of surfaces. Toronto: John Wiley \& Sons; 1988.

37. Born M and Wolf E. Principles of optics, Oxford: Pergamon Press; 1987.

38. Debe MK. Optical probes of organic thin films: photons-in and photons-out. Progress in Surface Science. 1987; 24(1-4):1-282. http://dx.doi.org/10.1016/0079-6816(87)90065-7.

39. Rodriguez-Llorente S, Aroca R and Duff J. Spectroscopic characterization of thin solid films of a bis(chlorobenzylimidope ryleneimido)octane derivative. Journal of Materials Chemistry. 1998; 8(3):629-632. http://dx.doi.org/10.1039/a707268f.

40. Kam A, Aroca R, Duff J and Tripp CP. Evolution of the molecular organization in bis ( $n$-propylimido)perylene films under thermal annealing. Chemistry of Materials. 1998; 10(1):172-176. http:// dx.doi.org/10.1021/cm970299t.

41. Antunes PA, Constantino CJL, Aroca R and Duff J. Reflection absorption infrared spectra of thin solid films. molecular orientation and film structure. Applied Spectroscopy. 2001; 55(10):1341-1346. http://dx.doi.org/10.1366/0003702011953450.

42. Kam AP, Aroca R, Duff J and Tripp CP. Role of water in the molecular reorientation on thermal annealing of bis $(n$ -propylimido)perylene films. Langmuir. 2000; 16(3):11851188. http://dx.doi.org/10.1021/la9816252.

43. Hädicke E and Graser F. Structures of eleven perylene-3,4:9,10bis(dicarboximide) pigments. Acta Crystallographica. Section C, Crystal Structure Communications. 1986; 42(2):189-195. http://dx.doi.org/10.1107/S0108270186096828.

44. Yanagi H., Toda Y. and Noguchi T. Photoelectrochemical behaviors of orientation-controlled thin-films of n, n'-substituted perylene-3,4/9,10-bis(dicarboximide). Japanese Journal of Applied Physics Part 1-Regular Papers Short Notes \& Review Papers, 1995, 34:3808-3813.

45. Sze SM and Ng KK. Physics of semiconductor devices. New Jersey: John Wiley \& Sons; 2007.

46. Olthuis W, Streekstra W and Bergveld P. Theoretical and experimental determination of cell constants of planarinterdigitated electrolyte conductivity sensors. Sensors and Actuators. B, Chemical. 1995; 24(1-3):252-256. http://dx.doi. org/10.1016/0925-4005(95)85053-8.

47. Volpati D, Machado AD, Olivati CA, Alves N, Curvelo AAS, Pasquini D, et al. Physical vapor deposited thin films of lignins extracted from sugar cane bagasse: morphology, electrical properties, and sensing applications. Biomacromolecules. 2011; 12(9):3223-3231. http://dx.doi.org/10.1021/bm200704m. PMid:21766835.

48. Tkachenko NV, Chukharev V, Kaplas P, Tolkki A, Efimov A, Haring K, et al. Photoconductivity of thin organic films. Applied Surface Science. 2010; 256(12):3900-3905. http:// dx.doi.org/10.1016/j.apsusc.2010.01.047.

49. Ji S, Wang H, Wang T and Yan D. A high-performance roomtemperature $\mathrm{NO} 2$ sensor based on an ultrathin heterojunction film. Advanced Materials. 2013; 25(12):1755-1760. http:// dx.doi.org/10.1002/adma.201204134. PMid:23381844.

50. Huang Y, Fu L, Zou W, Zhang F and Wei Z. Ammonia sensory properties based on single-crystalline micro/nanostructures of perylenediimide derivatives: core-substituted effect. The Journal of Physical Chemistry C. 2011; 115(21):10399-10404. http:// dx.doi.org/10.1021/jp200735m.

51. Jiang B-P, Guo D-S and Liu Y. Reversible and selective sensing of aniline vapor by perylene-bridged bis(cyclodextrins) assembly. The Journal of Organic Chemistry. 2011; 76(15):6101-6107. http://dx.doi.org/10.1021/jo2007576. PMid:21707090.

52. Huang Y, Fu L, Zou W and Zhang F. Probing the effect of substituted groups on sensory properties based on singlecrystalline micro/nanostructures of perylenediimide dyes. New Journal of Chemistry. 2012; 36(4):1080-1084. http://dx.doi. org/10.1039/c2nj20811c.

53. Huang Y, Zhang W, Wang J and Wei Z. Probing the sensory property of perylenediimide derivatives in hydrazine gas: coresubstituted aromatic group effect. ACS Applied Materials \& Interfaces. 2014; 6(12):9307-9313. http://dx.doi.org/10.1021/ am5016765. PMid:24897677.

54. Huang Y, Wang J, Fu L, Kuang W and Shi J. Effect of coresubstituted groups on sensing properties based on single micro/ nanorod of perylenediimide derivatives. Sensors and Actuators. B, Chemical. 2013; 188:411-416. http://dx.doi.org/10.1016/j. snb.2013.07.021. 
Appendix: FTIR spectra and AFM data.

\section{FTIR/ transmission mode}

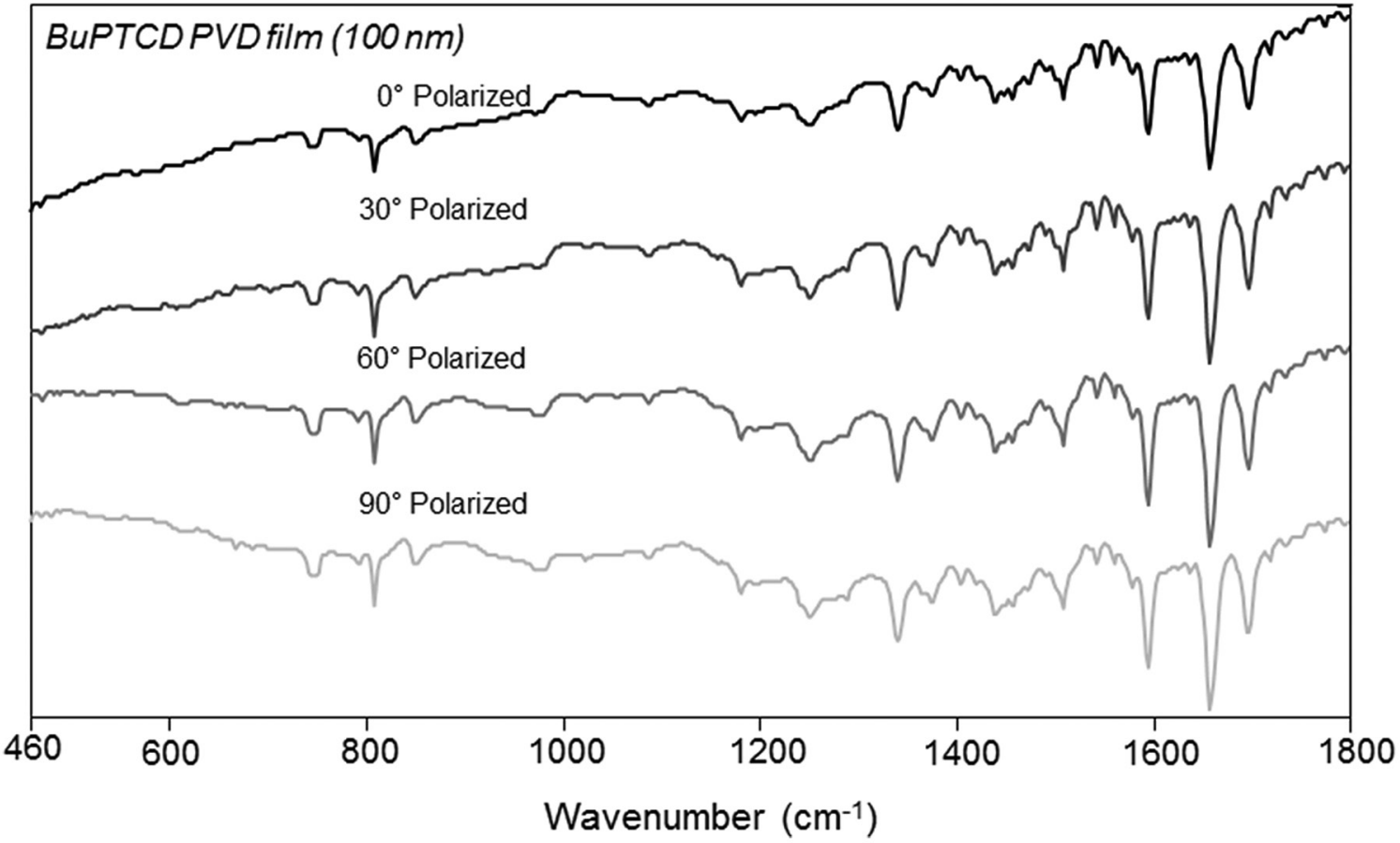

Figure 1S. Polarized FTIR spectra (transmission mode) with $0^{\circ}, 30^{\circ}, 60^{\circ}$ and $90^{\circ}$ recorded from $100 \mathrm{~nm}$ PVD film of BuPTCD deposited onto Ge.

\section{FTIR/ reflection mode}

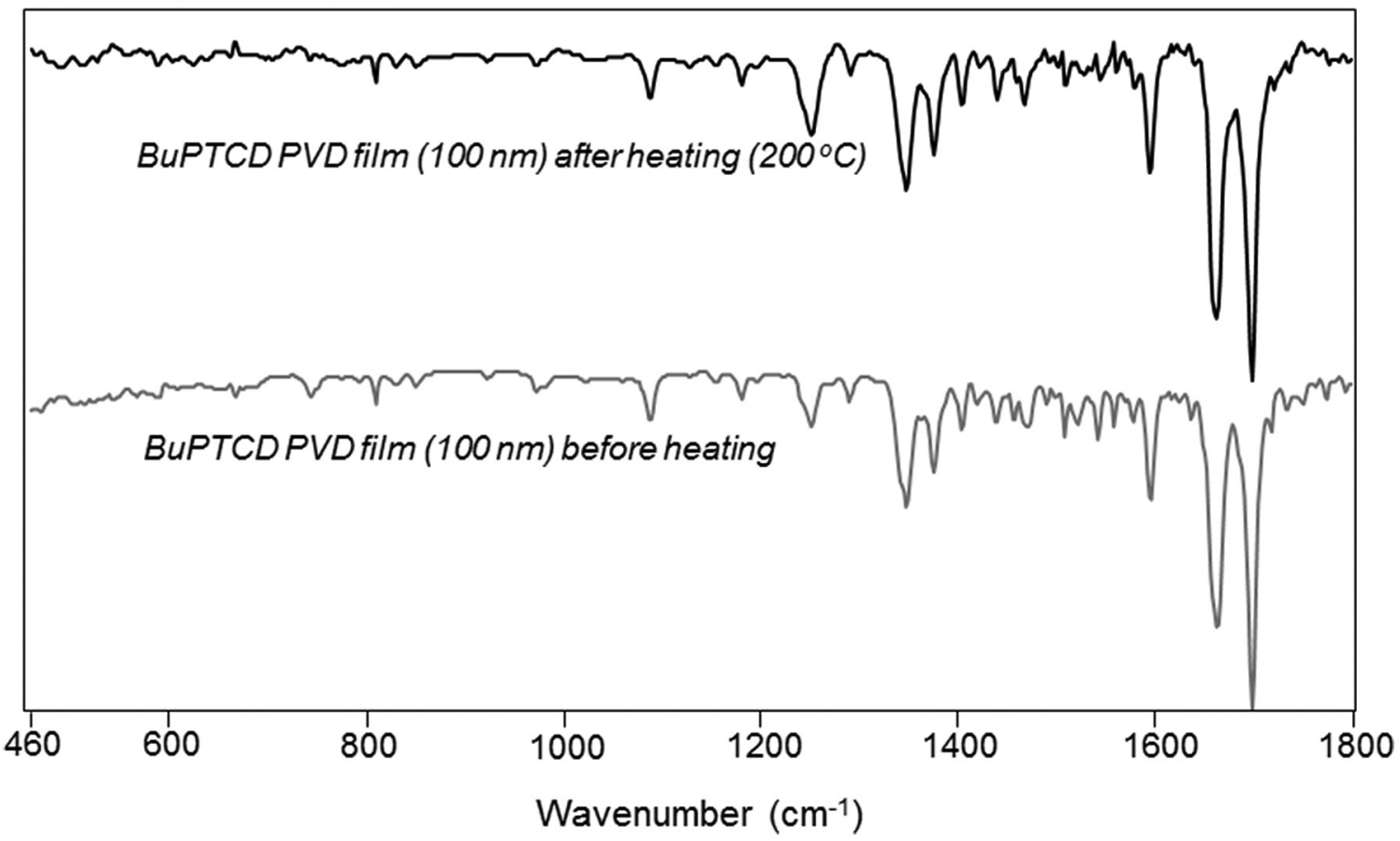

Figure 2S. FTIR spectra (reflection mode) recorded for the $100 \mathrm{~nm}$ PVD film of BuPTCD before and after annealing at $200^{\circ} \mathrm{C}$ for $2 \mathrm{~h}$. 